\title{
Effects of Hot Water Extraction Pretreatment on Physicochemical Changes of
}

\section{Douglas Fir}

\author{
Rui Zhu ${ }^{\text {a,b }}$, Vikram Yadama ${ }^{\text {b,c }} *$ \\ ${ }^{a}$ Materials Science and Engineering Program, Washington State University, Pullman, WA \\ 99164, USA \\ ${ }^{\mathrm{b}}$ Composite Materials and Engineering Center, Washington State University, Pullman, WA \\ 99164, USA \\ ${ }^{\mathrm{c}}$ Department of Civil and Environmental Engineering, Washington State University, Pullman, \\ WA 99164, USA \\ *Corresponding author. Tel.: +1 509335 6261; Fax.: +1 509 335-5077. \\ Email addresses: rui_zhu@wsu.edu (R. Zhu), vyadama@wsu.edu (V. Yadama).
}

\section{ABSTRACT}

Hot water extraction (HWE) is an autocatalytic pretreatment that can be effectively integrated into most of the conversion technologies for extracting hemicelluloses from woody biomass. The objective of this study was to understand the influence of pretreatment factors on removal of hemicelluloses from Douglas fir chips. Compositional change in biomass was analyzed with ion chromatography and further confirmed with Fourier transform infrared spectroscopy (FT-IR). Highest hemicellulose extraction yield (HEY) was estimated to be $67.44 \%$ at the optimum reaction time $(79 \mathrm{~min})$ and temperature $\left(180^{\circ} \mathrm{C}\right)$ by using response surface methodology (RSM). Experimental results show that the HEY increased from 19.29 to $70.81 \%$ depending on the reaction time (30-120 min) and the temperature $\left(140-180^{\circ} \mathrm{C}\right)$. Effects of the severity factor (SF) on the mass removal and compositional changes were also evaluated. Hygroscopicity and thermal stability of wood were improved after HWE pretreatment. Colorimetric analysis showed that temperature has a greater influence on color of the wood chips during HWE pretreatment than dwell time. HWE pretreatment shows great potential for extracting hemicelluloses and altering physicochemical properties of wood in an integrated biorefinery for diversification of product portfolio. 


\section{Keywords}

Hot water extraction ; Douglas fir ; Response surface methodology ; Hemicellulose ; Wood pretreatment ; Woody biomass

\section{Introduction}

Recently, second generation biofuels from lignocellulosic materials have attracted substantial attention due to an increased demand for fuels, rising environmental concerns, and the decreased availability of fossil fuels [1]. Lignocellulosic materials are the most abundant organic source on earth, with an annual production in the biosphere of about 170 billion metric tons [2]. Softwoods are one of the major lignocellulosic resources available, and represent a potentially large source of biomass for bioconversion [3]. Softwoods have higher lignin content compared to hardwoods. They also have more hemicelluloses with a higher mannose content and lower xylose content [4].

A typical biochemical pathway in biofuel production involves three main steps: pretreatment, enzymatic hydrolysis, and fermentation. The cellulose microfibrils are assembled by crystalline polymer chains that are constrained by a highly organized Van-der-Waals force and hydrogen bonding, which cannot be swelled or dissolved by common solvents [5]. In addition, the cellulose microfibrils are embedded in a matrix of hemicellulose and lignin, which acts as an interface. This complex composite must be at least partially deconstructed by pretreatment so that the polysaccharide fractions (mainly cellulose) can become more accessible and amenable to enzymatic hydrolysis. 
Over the past few decades, several pretreatment approaches have been developed to convert carbohydrates in lignocellulosic materials more efficiently into fermentable sugars. Generally, the approaches can be classified into biological, physical, chemical and physicochemical pretreatments, according to different forces or energy consumed in the pretreatment process [6]. Different pretreatment parameters alter several key properties of biomass. This appears to effect the recalcitrance of pretreated biomass, including resulting biomass constituents, cellulose crystallinity, ultrastructure, cellulose degree of polymerization, and accessibility [7]. However, there are still several unresolved issues in the pretreatment process. For instance, most existing pretreatments require energy-intensive size reduction from wood chips to particles of millimeters or less (fiber or powder) prior to or along with pretreatment in order to achieve satisfactory cellulose conversion efficiencies [8]. Typical size reduction energy consumption for fiberization wood chips is about 200-600 Wh electricity/kg oven dry wood [9]. Besides, hazardous chemical used during pretreatment increase the overall cost and can pose serious environmental problems.

One promising physico-chemical pretreatment is hot-water extraction (HWE), also described as autohydrolysis or autocatalytic. In this approach, biomass is treated with chemical-free and water-only media in a wide range of temperatures $\left(130-230{ }^{\circ} \mathrm{C}\right)$ and pretreatment times (from a few seconds to several hours) [10]. It combines the hydrolytic properties of water with the actions of released organic acids to catalyze hydrolysis reactions [11]. The process causes hemicellulose depolymerization (mainly converted into soluble oligomers as a major reaction product) and lignin transformation due to the high temperature, thus increasing the potential of cellulose hydrolysis. Besides, the HWE pretreatment has great scalability, since the process can use existing infrastructures (such as digesters) in the pulp and paper industry. 
Overall, the HWE process has been considered as a simple, low-cost and environmental friendly pretreatment technology. It has great potential to be integrated into a biorefinery processes, as presented in Fig. 1. After HWE pretreatment, there are two main product streams: residual chips and extracted aqueous solution. The structural components of residual chips (mostly cellulose and lignin) remain largely intact during and after HWE, but become more chemically reactive and more energy-dense (Btu/ton), lower in ash content and substantially less hydrophilic [12]. There properties improvements have significant implications for HWE in the manufacture of conventional wood-derived products such as paper, fiberboard, particleboard, wood plastic composites (WPCs) and fuel pellets [13-16]. Removal of hemicelluloses increases the mean pore size of the substrate and therefore increases the accessibility and the probability of the cellulose to be hydrolyzed. Recovery of nanocellulose can also improve due to relatively increased cellulose content, along with more accessible regions of amorphous cellulose. The extracted aqueous solution, on the other hand, contains primarily saccharides from hemicelluloses and a small portion of inhibitory byproducts such as furfural, acetic acid and other organic acids. From this stream, the dissolved hemicellulose can be further converted to commodity chemicals and materials after separation and recovery steps. C-5 and C-6 sugars, which can be separated from the dissolved oligomer sugars, are essential feedstock sources for fermentation.

Many studies have been carried out on effects of HWE on hardwoods species such as aspen [17], maple [18] and oaks [19]. Limited research has been conducted on the effects of HWE on softwoods $[13-15,20]$. Softwoods are more challenging due to their unique characteristics such as greater difficulty of delignification and higher hemicellulose content. Douglas fir is a refractory species, which is difficult to impregnate with water even under pressure. The main 
objective of this research is to investigate the effects of the severity factor (SF) on compositional changes and physicochemical (hygroscopic, thermal and colorimetric) properties of Douglas fir. This study highlights the potential of using the HWE technique for lignocellulosic materials to facilitate downstream processing for production of various co-products and biofuels.

\section{Materials and Methods}

\subsection{Raw materials}

Douglas fir wood chips were acquired from Vaagen Brothers Lumber Inc. (Colville, WA) and screened with a Black-Clawson Gyratory screening machine to sizes from $4.75 \mathrm{~mm}$ to 25.40 $\mathrm{mm}$. The screened chips were dried to $15 \%$ moisture content (MC) in a forced air dryer and stored in the conditioned room (equilibrium $\mathrm{MC}=12 \%$ ) before further processing. Screened chips were used directly for HWE pretreatment without further size reduction or separation. Particle size analysis showed that $90.1 \mathrm{wt} \%$ of the wood chips ranged between 15.88 to $4.75 \mathrm{~mm}$, and $9.9 \mathrm{wt} \%$ ranged from 25.40 to $15.88 \mathrm{~mm}$.

\subsection{Protocol of hot water extraction pretreatment}

HWE pretreatment was conducted in a $2 \mathrm{~L}$ Parr batch pressure reactor (controller model 4842). Each batch of HWE consisted of 50 g oven-dry (OD) wood chips. The moisture content of wood chips was measured before weighting and subtracted from the liquid-solid ratio (LSR) calculation. The reactor took 20-30 min (warming-up time) to reach the target temperature. HWE pretreatment was carried out for a selected time, excluding the warm-up time. The reactor was immediately cooled down by soaking in a water bath at the end of the desired reaction time. Liquid and solid fractions were separated by filtration using vacuum pump equipment. Liquid 
fractions (hydrolysate) were refrigerated for further analysis. Solid fractions were washed with deionized water several times and then oven-dried overnight at $103 \pm 2{ }^{\circ} \mathrm{C}$. Oven dry weight (ODW) of the solids was recorded and used to calculate mass removal as follows:

$$
\text { Mass removal }=\left(W_{\text {before }}-W_{\text {after }}\right) / W_{\text {before }} \times 100 \%
$$

Where $W_{\text {after }}$ is the ODW of solids after pretreatment, and $W_{\text {before }}$ is the ODW of solids before pretreatment. Effectiveness of HWE process was evaluated using the severity factor (SF) in order to summarize in one variable the effects of main parameters (reaction time and temperature). SF value $\left(\log \left(R_{0}\right)\right)$ were calculated as shown in Equation (2) [21], where $t$ is the reaction time (min), $T$ is the reaction temperature $\left({ }^{\circ} \mathrm{C}\right), 100$ is the temperature of reference and 14.75 is an empirical parameter related with activation energy, assuming pseudo-first order kinetics.

$$
\log \left(R_{\mathrm{o}}\right)=\log \left[t \exp \left(\begin{array}{ll}
T & 100
\end{array}\right) / 14.75\right]
$$

\subsection{Experimental design and statistical analysis}

Reaction time, temperature and liquid-solid ratio (LSR) are the most critical parameters for hydrothermal pretreatment. Based on our preliminary study (reaction time of $75 \mathrm{~min}$ and temperature at $160^{\circ} \mathrm{C}$ with $\mathrm{LSR}$ varying from 3 to 6), LSR above 4.5 did not result in significant increase in the removal of xylose/mannose content from the solid fractions. The changes in mass removal $(12.54 \%$ to $15.34 \%)$ and xylose/mannose content in the solid fractions (10.65 \% to $12.93 \%)$ are both limited as the LSR varied from 3 to 6 . In fact, xylose/mannose content in the solid fractions had the lowest value (10.65\%) as LSR equals to 4.5. Therefore, reaction time and temperature are the two major pretreatment parameters investigated in this study, and LSR was kept at 4.5 in all formulations. For optimization of HEY as defined in section 2.4, a response surface methodology (RSM) was applied to form the experimental design using Design-Expert 8.0 (Stat-ease Inc., Minneapolis, USA). The independent variables were reaction time, $X_{1}$, (30- 
$120 \mathrm{~min})$ and temperature, $X_{2},\left(140-180^{\circ} \mathrm{C}\right)$ at three variation levels $(-1,0$, and +1$)$. Ranges and levels of the independent variables were selected based on our preliminary study and literature [22]. A total of twelve combinations (including four replicates at the center point with each value coded as 0) were formed, and experiments were conducted in random order. The actual and coded values of the two independent variables together with the responses are shown in Table 1. The responses evaluated were SF, mass removal, and HEY. The second-order polynomial mathematical model was applied to estimate the response HEY:

$$
Y={ }_{0}+{ }_{1} x_{1}+{ }_{2} x_{2}+{ }_{12} x_{1} x_{2}+{ }_{11} x_{1}^{2}+{ }_{22} x_{2}^{2}
$$

Where $Y$ is the predicted value of HEY, $x_{1}$ and $x_{2}$ are the coded values of independent variables (reaction time and temperature), $\beta_{0}$ is a constant coefficient, $\beta_{1}$ and $\beta_{2}$ are the linear coefficients, $\beta_{12}$ is the interaction coefficient, and $\beta_{11}$ and $\beta_{22}$ are the quadratic coefficients. The quality of the fit of the polynomial model equation was evaluated by the coefficient of determination $R^{2}$ and the statistical significance was evaluated with the $F$-test for analysis of variance (ANOVA) with a $95 \%$ confidence level. All data analyses were conducted using Design-Expert 8.0.

\subsection{Analytical methods for chemical composition}

Untreated and HWE treated Douglas fir chips were milled using a Thomas Wiley mill to pass through a 40-mesh screen, sealed in a plastic bag, and kept in a refrigerator for further analysis. The chemical components of all formulations were determined following National Renewable Energy Laboratory's (NREL) laboratory analytical procedures (LAP) (001-005). Fig. 2 shows the schemes of analytical methods for chemical compositions of both solid residues and hydrolysate. In brief, solid residues first underwent a two-step acid hydrolysis. In the first step, $72 \%(\mathrm{w} / \mathrm{w}) \mathrm{H}_{2} \mathrm{SO}_{4}$ at $30{ }^{\circ} \mathrm{C}$ for 60 min was used. In the second step, the reaction mixture was 
diluted to $4 \%$ (w/w) $\mathrm{H}_{2} \mathrm{SO}_{4}$ and autoclaved at $121{ }^{\circ} \mathrm{C}$ for $1 \mathrm{~h}$. After cooling, the acid insoluble lignin (AIL) was collected by filtration, washed with deionized water until neutral $\mathrm{pH}$ solution was obtained, and dried at $105^{\circ} \mathrm{C}$ until it reached a constant weight. Structural monosaccharides (glucose, xylose, mannose, arabinose and galactose) in the solid residues were determined with high-performance anion exchange chromatography with pulsed amperometric detection (HPAEC-PAD) (ICS-3000, Dionex, Sunnyvale, CA). Compared to high-performance liquid chromatography (HPLC), the HPAEC-PAD method avoids the derivatization of the monosaccharides. Monosaccharides are separated on CarboPac PA 20 Guard (4 x 50 mm) and Analytical (4 x $250 \mathrm{~mm})$ Columns at ambient temperature $\left(25^{\circ} \mathrm{C}\right)$ and detected with an ED 40 electrochemical detector. The saccharides were quantified with reference to sugar recovery standards, which were autoclaved at $121^{\circ} \mathrm{C}$ for $1 \mathrm{~h}$ prior to analysis to compensate for sugar destruction during heating. HEY was calculated using the following equation:

$$
\mathrm{HEY}=\left(W_{\text {untreated }}-W_{\text {treated }}\right) / W_{\text {untreated }} \times 100 \%
$$

where $W_{\text {untreated }}$ is wt $\%$ of all hemicellulose monosugars in the untreated Douglas fir, and $W_{\text {treated }}$ is $\mathrm{wt} \%$ of all hemicellulose monosugars in the solid residues. Monosaccharide concentrations in the hydrolysate were also quantified. Briefly, the hydrolysate were autoclaved with $4 \%$ w/w) $\mathrm{H}_{2} \mathrm{SO}_{4}$ at $121^{\circ} \mathrm{C}$ for $1 \mathrm{~h}$ to convert oligomeric sugars into monomeric sugars completely, and monomeric sugar concentrations were measured with HPAEC as described above. All analytical determinations were performed in duplicate, and average results are shown in Table 2.

\subsection{Moisture absorption}

The moisture absorption rate of wood chips was measured in a humidity chamber (Russells G64). The chamber was set at $30{ }^{\circ} \mathrm{C}$ and $90 \%$ relative humidity $(\mathrm{RH})$. Prior to the absorption test, 
wood chips were oven-dried at $103 \pm 2{ }^{\circ} \mathrm{C}$ for $24 \mathrm{~h}$. About $5 \mathrm{~g}$ of wood chips were placed in a petri glass dish and placed in the humidity chamber for a minimum of $5 \mathrm{~h}$. The weight of the sample was measured every $10 \mathrm{~min}$ for the first hour, followed by every $30 \mathrm{~min}$ for the next $4 \mathrm{~h}$. The petri dish was covered with a glass cap during weighing to prevent moisture loss. Three replicates were measured for each sample, and average values were reported. The kinetics of moisture sorption are represented with the ASABE S448.1 formulation for thin-layer drying

$$
\left(M-M_{e}\right) /\left(M_{i}-M_{e}\right)=e^{-k t}
$$

where $M$ is the instantaneous moisture content (decimal, on a dry basis), $M_{\mathrm{e}}$ is the equilibrium moisture content (decimal, on a dry basis), and $M_{\mathrm{i}}$ is the initial moisture content (decimal, on a dry basis). The coefficient $\mathrm{k}$ is an absorption rate constant, and $\mathrm{t}$ is the exposure time (minutes).

\subsection{Thermogravimetric analysis (TGA)}

TGA was carried out on a TA instruments SDT 600 to investigate the general characteristics of lignocellulose decomposition. A sample of approximately $8 \mathrm{mg}$ wood flour was loaded into an alumina pan and used for each run. Samples were heated from $25^{\circ} \mathrm{C}$ to $550{ }^{\circ} \mathrm{C}$ at a heating rate of $10{ }^{\circ} \mathrm{C} / \mathrm{min}$ in a nitrogen atmosphere with a constant flow of $100 \mathrm{~mL} / \mathrm{min}$. Three replicates of each sample were measured to verify experimental repeatability.

\subsection{Fourier Transform Infrared Spectroscopy (FT-IR)}

FT-IR analysis was performed to analyze the chemical changes of biomass after HWE pretreatment using a Thermo Nicolet Nexus 670 spectrometer. An Attenuated Total Reflectance (ATR) cell was mounted onto the spectrometer. Spectra were ATR corrected and normalized with Thermo Nicolet Software (6.0.2). A small amount of wood flour sample was placed on the 
Germanium (Ge) surface of the ATR cell. The spectra were collected over the range of 4000-400 $\mathrm{cm}^{-1}$ with 32 scans at a resolution of $2 \mathrm{~cm}^{-1}$.

\section{$2.8 \quad$ Colorimetric analysis}

Color measurements of wood flour were recorded using a StellarNet EPP2000 UV-Vis spectrometer (190 to $850 \mathrm{~nm}$ ), krypton light source (SL1, StellarNet), with a diffuse reflection fiber optic probe in accordance with ASTM D 2244 [23]. Spectrometer's SpectraWiz software transforms spectral data into CIELAB color coordinates $\left(\mathrm{L}^{*}, \mathrm{a}^{*}\right.$ and $\left.\mathrm{b}^{*}\right)$ based on a D65 light source. Wood flour was spread in the aluminum dish before test. Three replicates were measured at different locations in the dish. The total change in color $\left(\Delta E_{\mathrm{ab}}\right)$ was calculated using the following Euclidean distance equation:

$$
E_{a b}=\sqrt{L^{2}+a^{2}+b^{2}}
$$

where $\Delta L, \Delta a$, and $\Delta b$ represent the differences between the initial and final values of $L^{*}, a^{*}$, and $b^{*}$, respectively. An increase in $L$ means the sample is lighter in color. A positive $\Delta a$ signifies a color shift toward red, and a negative $\Delta a$ signifies a color shift toward green. A positive $\Delta b$ signifies a shift toward yellow, and a negative $\Delta b$ signifies a shift toward blue.

\section{Results and Discussion}

\subsection{Changes in biomass composition depending on pretreatment conditions}

Ion-chromatography results were used to determine the compositional changes of the biomass. The chemical composition of extract-free solid substrates and monosugar concentrations in hydrolysate under different pretreatment conditions were summarized in Table 2. On average, the untreated Douglas fir showed the following composition [\% dry weight basis (dwb)]: 
cellulose (glucan), 45.18; hemicellulose, 18.62 (xylan/mannan, 14.29; arabinan, 1.21 and galactan, 3.12); acid-insoluble lignin, 24.41; acid soluble lignin, 0.60; extractives, 5.50; ash, 0.50. The Douglas fir composition in this study is comparable with the typical value of Douglas fir in the literature [24].

Response surface of mass removal using the linear model is shown in Fig. 3. Results confirm that both temperature and extraction time had major influence on the mass removal of HWE process. Generally, mass removal varied from only $\sim 3 \%$ under a lower temperature $\left(140{ }^{\circ} \mathrm{C}\right)$ and a shorter extraction time $(30 \mathrm{~min})$ to $\sim 23 \%$ under a high temperature $\left(180{ }^{\circ} \mathrm{C}\right)$ and a longer extraction time (120 min). Mass removal increased with increasing temperature and/or extraction time in the entire pretreatment condition ranges. These results demonstrate that harsher pretreatment conditions solubilized more hemicelluloses. Similar result was observed by Lu et al [17] for aspen wood chips. It is well known that Douglas fir is a refractory species, which is difficult to impregnate with water even under pressure. However, harsher conditions have a compounded effect by providing more time and energy to assist the hydrolysis, and by also lowering the $\mathrm{pH}$ due to the liberation of acetyl and uronyl groups as acetic and uronic acid from the hemicellulose [25].

Effects of pretreatment conditions on the compositional changes of pretreated Douglas fir are summarized in Fig. 4. Single factor effects (such as temperature) were observed while other factors (such as time and LSR) were set at the center point values. Generally, a progressive increase of the Klason lignin content in the pretreated substrates was observed at higher temperatures and longer time, essentially due to the relative decrease in the amount of 
hemicellulose. The solubilization of water-soluble biomass components into hydrolysate resulted in a cellulose enriched solid residues compared to the untreated biomass. Hence, the glucan content of HWE treated solid residues was relatively higher than that of untreated Douglas fir (47.81\%), ranging from 49.44 to $58.48 \%$. As temperature and time increased, the xylan/mannan content in the solid residues decreased as a result of a greater release into the hydrolysate. Increasing temperature resulted in an increase in pressure, better penetration of the hot water into the cell walls, higher hydrolysis of hemicellulose and higher mass loss [26].

Likewise, as the pretreatment time increased, more hot water could penetrate the cell walls, resulting in more hemicellulose dissolving in the liquid fractions. Developing a HWE pretreatment based on low LSR results in more efficient water usage and thus in lower capital and operating costs (electricity and/or steam). Low LSR also raises the acetic acid (catalyst) concentration in the reaction medium promoting the release of acetyl groups, which favors autohydrolysis of the lignocellulosic material [27]. However, a high LSR could increase mass transfer rate, which control the reaction rate in the acid hydrolysis. For preliminary studies of LSR for Douglas fir in this study, both lignin, glucan and xylan/mannan content first decreased and then increased with increasing LSR. Further studies are needed to explain this observation. LSR of 4.5 is more favorable, considering the fact that xylan/mannan content reached the lowest value at this LSR level and that it compromised the advantages of both low and high LSR.

\subsection{Effects of pretreatment conditions on monosugar recovery from hydrolysate}

Liquid fractions from HWE pretreatment were hydrolyzed, and total monosugar concentration in the hydrolysate was analyzed and plotted against SF (Fig. 5). The overall trends suggest that 
more severe conditions resulted in the solubilization of more saccharides. Xyl/mannose are the main monomer sugars in the hydrolysate, confirming that hemicelluloses were predominantly hydrolyzed over cellulose during HWE pretreatment. Generally, more glucose was dissolved in the hydrolysate as the SF increased. However, unlike mass removal, the total monosugar concentration in the hydrolysate did not show a linear relationship with SF. The three lowest monosugar concentrations were obtained when $140{ }^{\circ} \mathrm{C}$ was applied in the HWE pretreatment (SF of $2.65,3.05$ and 3.26). These results indicate that temperature was a key parameter significantly affecting pretreatment yield and dissolution of hemicelluloses. We hypothesized that the amount of catalysts hydronium ions $\left(\mathrm{H}_{3} \mathrm{O}^{+}\right)$generated in situ by auto-ionization of water and the acetic acid generated by hydrolysis of the hemicelluloses were limited below $140{ }^{\circ} \mathrm{C}$. Only in-organics such as extractives and very small amount of saccharides were dissolved in the hydrolysate under these pretreatment conditions.

Based on the compositional analysis of the solids and hydrolysate above, a typical mass balance of HWE is developed to show a clear overview of this pretreatment [28]. Note that all process yields were normalized to a common basis of $100 \mathrm{~kg}$ of untreated, extractive free Douglas fir as the starting material. Because some of the components, such as extractives, were not analyzed, it is common that there will be some weight difference between the total weight of the biomass analyzed and the sum of the components in the biomass. HWE recovered $85.66 \%$ of the initial biomass and removed $\sim 50 \%$ hemicelluloses, but selectively preserved most of the cellulose (Fig. 6). About $23 \%$ of hemicelluloses dissolved in the hydrolysate remained in their sugar state and could be recovered without additional processing steps. 


\subsection{Statistical analysis and optimization of $\mathrm{HEY}$}

The second-order polynomial model expressed in Equation (7) represent the HEY $(Y)$ as a function of the coded values of reaction time $\left(x_{1}\right)$ and temperature $\left(x_{2}\right)$.

$$
Y=41.01+5.70 x_{1}+16.76 x_{2} \quad 4.49 x_{1} x_{2} \quad 6.76 x_{1}^{2}+9.61 x_{2}^{2}
$$

ANOVA results listed in Table 3 reveal that second-order polynomial model was adequate for

prediction of HEY within the range of independent variables. The $R^{2}$ value was 0.887 , indicating that only $11.3 \%$ of the total variations were not explained by the model. The $p$-value of the model (0.0082) is less than 0.05 , indicating that the proposed model was significant. Among all the model terms, only $x_{2}$ is significant $(p<0.05)$, which corresponds well with the monosugar concentration results in section 3.2. The ANOVA table also shows that there is no strong interaction between time and temperature during autohydrolysis if only considering HEY as the response. Response surface of this model was plotted in order to obtain the optimal conditions for the maximum HEY (Fig. 7). HEY value was estimated to be $67.44 \%$ at the optimal point (time: 79 min, temperature: $180^{\circ} \mathrm{C}$ ) with desirability index of 0.935 by utilizing numerical optimization method. The experimental and predicted HEY are presented in Table 1. The HWE conducted at $120 \mathrm{~min}$ and $180^{\circ} \mathrm{C}$ (serial number 5) has lower experimental HEY than that of 30 min and $180{ }^{\circ} \mathrm{C}$ (serial number 2). At severe temperature of $180^{\circ} \mathrm{C}$, more hemicelluloses were degraded into inhibitors as reaction time increased.

\subsection{Physicochemical characterization of solid residues}

\subsubsection{Moisture absorption}

Moisture sorption of HWE wood chips was evaluated as a decrease in hygroscopicity and water uptake can improve dimensional stability and performance of wood and wood-based composites 
[29]. Typical plots (Fig. 8) of the moisture content (MC) of wood chips versus time during moisture absorption test in the humidity chamber indicate that the moisture absorption process includes two stages: a rapid absorption ( first $60 \mathrm{~min}$ ) and a slower, but relatively linear, absorption ( after $60 \mathrm{~min}$ ). Among all the formulations, untreated Douglas fir had the highest MC of $19.5 \%$ after exposing to the humid conditions for $4 \mathrm{~h}$. Hydroxyl groups in the main wood components (cellulose, hemicellulose, and lignin) can readily form hydrogen bonds with water, causing a high rate of water absorption of wood. HWE pretreatment extracted some of the hemicellulose, resulting in a decrease of hydroxyl groups in the wood. Therefore, the moisture absorption of wood decreased after HWE.

The absorption rate k of untreated and HWE treated wood chips with different pretreatment conditions are also presented in the legends in Fig. 8. The absorption rate of the HWE treated wood chips ranged from 0.0062 to $0.0086 \mathrm{~min}^{-1}$, without a clear trend with SF. Similar results were reported for absorption rate of pellets made with steam treated Douglas fir [30]. It was worth noting that although wood chips treated for $30 \mathrm{~min}$ had a mass removal of only $9.4 \%$, they

had the lowest water absorption rate of $0.0062 \mathrm{~min}^{-1}$. As mass removal further increased, formation of larger pores increases the capillary motion of water, and thus increases the absorption rate of wood. Zhang et al. [29] showed that HWE treated strands with mass removal of $9.5 \%$ have the lowest water uptake. They also deduced that samples with less water uptake have lower surface free energy and a larger contact angle.

\subsubsection{Thermal properties}

The thermal stability of wood is critical for the manufacture of conventional wood derived products. Based on the thermogravimetric (TG) and derivative thermogravimetric (DTG) curves 
of untreated and HWE treated wood flour (Fig. 9), generally HWE treated Douglas fir is more thermally stable in nearly entire temperature range compared to untreated Douglas fir. Hemicellulose is the least stable polymer in the wood, which starts to decompose at about 225 ${ }^{\circ} \mathrm{C}$. The TG curves dropped dramatically when the heating temperature increased from 250 to $400{ }^{\circ} \mathrm{C}$. Thermal stability increased continuously with increasing pretreatment temperature from 140 to $180^{\circ} \mathrm{C}$, as evidenced by gradual increase in higher decomposition temperature (Fig. 9(b)). For example, the carbon residue's degradation temperature ( $c a .50 \%$ weight loss) was $356^{\circ} \mathrm{C}$ for the untreated Douglas fir. This value increased from 363 to $370{ }^{\circ} \mathrm{C}$ as pretreatment temperature increased from 140 to $180^{\circ} \mathrm{C}$. The effect of reaction time on thermal stability of wood is not significant compared to that of temperature (Fig. 9(a)). Interestingly, the TG curves showed a slight increase in amount of residuals at a high temperature between 400 and $600{ }^{\circ} \mathrm{C}$ compared to untreated Douglas fir. This may be due to condensation and repolymerization in the lignin due to the acidity created during pretreatment, leading to new lignin structures with more stability [31].

The main asymmetric DTG peak at the thermolysis temperature range of $220-370{ }^{\circ} \mathrm{C}$ overlaps with individual component peaks for decomposition of cellulose and hemicellulose [32]. Hemicellulose degradation occurred from 275 to $345{ }^{\circ} \mathrm{C}$, with a maximum decomposition rate at $\sim 320^{\circ} \mathrm{C}$. Due to the removal of hemicelluloses, a less pronounced hemicellulose shoulder was observed in all curves of HWE treated Douglas fir. The shoulder completely disappeared for HWE treated wood at $180{ }^{\circ} \mathrm{C}$, which has the highest mass removal of $20.86 \%$. Under this severe condition, most of the hemicellulose sugars were extracted into the hydrolysate. These observations are consistent with results reported in the literature [33], where the overlapped double peak distribution evolved into a single-peak distribution as HWE pretreatment 
temperature increased from 160 to $200{ }^{\circ} \mathrm{C}$. The degradation rate of hemicelluloses increased strongly with the increasing torrefaction temperature [34]. The higher degradation rate could lead to higher hemicellulose removal, as revealed in DTG curves. Meanwhile, the maximum rate of thermal decomposition (around $360^{\circ} \mathrm{C}$ ) [35] of all HWE pretreated Douglas fir increased in comparison to that of untreated Douglas fir, showing the relative higher cellulose content, as demonstrated in section 3.1.

\subsubsection{ATR-FTIR}

Chemical fingerprinting of Douglas fir before and after HWE pretreatment were measured with ATR-FTIR spectroscopy. Many sharp and discrete absorption bands were observed in the fingerprint region (between 1800-900 $\mathrm{cm}^{-1}$ ) due to various functional groups in wood constituents (Fig. 10). The main assignments of the functional groups in this region are listed in Table 4. The absorbance peak at $1733 \mathrm{~cm}^{-1}$ is generally assigned to $\mathrm{C}=\mathrm{O}$ stretching, mainly originating from carbonyl groups in hemicellulose [36]. The intensity of this peak decreased significantly after HWE pretreatment compared to other peaks. As the pretreatment temperature increased from 140 to $180^{\circ} \mathrm{C}$, the peak gradually decreased and became an almost invisible shoulder at $180^{\circ} \mathrm{C}$. As discussed in section 3.1 , HWE pretreatment at $180^{\circ} \mathrm{C}$ has the highest mass removal of $20.86 \%$ and least xylan/mannan content of $5.47 \%$. Therefore, the peak changes at $1733 \mathrm{~cm}^{-1}$ confirmed that the hemicellulose content decreased as pretreatment temperature increased. Note that the peak \#7, \#11 and \#12 can be assigned to functional groups both in cellulose and hemicelluloses. Therefore, the height of those peaks can not be used to compare hemicellulose content in biomass after different pretreatment temperature. The absorbance peaks at $1606 \mathrm{~cm}^{-1}$ and $1509 \mathrm{~cm}^{-1}$ are related to aromatic ring skeletal vibration [36]. Those two peaks 
of HWE treated Douglas fir showed a slightly higher intensity, indicating greater vibration of aromatic rings and higher lignin content. According to Kataoka and Kondo [37], the IR crystallinity index (CrI) of cellulose was evaluated as the intensity ratio between IR absorptions at 1427 and $895 \mathrm{~cm}^{-1}$, which are assigned to $\mathrm{CH}_{2}$ bending mode and deformation of anomeric $\mathrm{CH}$, respectively. They have also shown a good correlation between IR and XRD CrI, regardless of the different crystalline form $\mathrm{I}_{\alpha}$ and $\mathrm{I}_{\beta}$. While absorbance is already normalized, it is still difficult to quantify the peak height precisely to calculate the intensity ratio. Therefore, conclusions of CrI changes could not be drawn from FT-IR data. In summary, the FT-IR data showed that cleavage of acetyl groups in hemicelluloses and re-deposition of lignin occurred during the HWE process. However, due to the heterogeneous nature of the plant cell wall, direct assessment of chemical changes at the molecular level cannot be accomplished by using FT-IR spectroscopy alone [38].

\subsubsection{Colorimetric analysis}

Color is an important visual attribute for materials. A simple color measurement of wood could provide a quick estimation of its potential as a feedstock for wood derived products. Analysis of the effects of pretreatment conditions on changes in lightness $(\Delta L)$ and the total color change $\left(\Delta E_{a b}\right)$ of wood flour (Fig. 11) indicates a decrease in $\Delta L$ after HWE treatment, and a more obvious decreasing trend when the reaction temperature increased from 140 to $180{ }^{\circ} \mathrm{C}$. All HWE treated Douglas fir show positive $\Delta E_{a b}$ values, which indicates that wood became darker after HWE, regardless of the pretreatment conditions. The $\Delta E_{a b}$ value is suggested to be an indicator of overall chemical modification [39]. Oxidative and hydrolytic reactions are primarily considered to be the cause for the production of chromophores during thermal treatment of 
wood, where hydrolytic reactions are generally the dominant process when moisture is present [40]. During HWE pretreatment, carbonic acids (mainly acetic acid) will be formed as a result of the cleavage of the acetyl groups of particular hemicelluloses. Such chemical changes resulted in the increase in $\Delta E_{a b}$ relative to untreated wood [41].

The Tukey multiple comparison test $(\alpha=0.05)$ indicated that temperature had a significant impact on discoloration of wood, as shown in Fig. 11(c). Although HWE treatment at $180{ }^{\circ} \mathrm{C}$ had highest mass removal $(20.86 \%)$, wood chips under this pretreatment condition turned darker in color. Interestingly, $\Delta E_{a b}$ increased gradually as the reaction time increased from 30 to 75 min, and further increase in the reaction time had only minimal effects on color changes. Therefore, if retaining the color of wood fiber is important, a better strategy to sufficiently remove hemicellulose is prolonging the pretreatment (above $75 \mathrm{~min}$ ) at a relatively low temperature (160 $\left.{ }^{\circ} \mathrm{C}\right)$.

\section{Conclusions}

Hot water extraction (HWE) pretreatment of Douglas fir wood chips was conducted in a 2L Parr reactor at different severity factor $(\mathrm{SF})$. A second-order polynomial model was formed, and the maximum hemicellulose extraction yield (HEY) as estimated to be $67.44 \%$ at the optimum point (time: $79 \mathrm{~min}$, temperature: $180{ }^{\circ} \mathrm{C}$ ). Chemical compositions and FT-IR analysis confirmed that hemicelluloses were partially dissolved in the hydrolysate. HWE pretreatment reduced the moisture absorption of wood. TGA indicated that thermal stability of wood was improved significantly after HWE pretreatment Temperature had a stronger impact on the color changes of wood compared to that of reaction time. HWE has great potential to be included in an integrated 
system of technologies to derive chemical byproducts (such as acetic acid and methane), co-

products (for example, fuel pellets, hemicellulose-based sugars for conversion into biofuels and biopolymers), and more hydrophobic wood chips for further processing into durable wood composites without compromising their mechanical performance.

\section{Acknowledgments}

The authors are grateful for financial support from the USDA National Institute of Food and Agriculture. Grant No. 2011-68005-30416.

\section{References}

[1] A.J. Ragauskas, C.K. Williams, B.H. Davison, G. Britovsek, J. Cairney, C.A. Eckert, et al., The Path Forward for Biofuels and Biomaterials, Science. 311 (2006) 484-489. doi:10.1126/science.1114736.

[2] D.L. Klass, Biomass for Renewable Energy, Fuels, and Chemicals, Elsevier Science, 1998.

[3] W.E. Mabee, D.J. Gregg, C. Arato, A. Berlin, R. Bura, N. Gilkes, et al., Updates on Softwood-to-Ethanol Process Development, Applied Biochemistry and Biotechnology. 129 (2006) 55-70. doi:10.1385/ABAB:129:1:55.

[4] W.-S. Lim, J.-W. Lee, Influence of pretreatment condition on the fermentable sugar production and enzymatic hydrolysis of dilute acid-pretreated mixed softwood, Bioresource Technology. 140 (2013) 306-311. doi:10.1016/j.biortech.2013.04.103.

[5] R. Ibbett, S. Gaddipati, S. Hill, G. Tucker, Structural reorganisation of cellulose fibrils in hydrothermally deconstructed lignocellulosic biomass and relationships with enzyme digestibility, Biotechnol Biofuels. 6 (2013) 1-16. doi:10.1186/1754-6834-6-33.

[6] P. Alvira, E. Tomás-Pejó, M. Ballesteros, M.J. Negro, Pretreatment technologies for an efficient bioethanol production process based on enzymatic hydrolysis: A review, Bioresource Technology. 101 (2010) 4851-4861. doi:10.1016/j.biortech.2009.11.093.

[7] Y. Pu, F. Hu, F. Huang, B.H. Davison, A.J. Ragauskas, Assessing the molecular structure basis for biomass recalcitrance during dilute acid and hydrothermal pretreatments, Biotechnol Biofuels. 6 (2013). doi:10.1186/1754-6834-6-15.

[8] J. Gao, D. Anderson, B. Levie, Saccharification of recalcitrant biomass and integration options for lignocellulosic sugars from Catchlight Energy's sugar process (CLE Sugar), Biotechnol Biofuels. 100 (2013) 2411-2418. doi:10.1016/j.biortech.2008.10.057.

[9] D. Schell, C. Harwood, Milling of lignocellulosic biomass, Applied Biochemistry and Biotechnology. 45-46 (1994) 159-168-168. doi:10.1007/BF02941795.

[10] M. Saska, E. Ozer, Aqueous extraction of sugarcane bagasse hemicellulose and 
production of xylose syrup, Biotechnol. Bioeng. 45 (1995) 517-523.

doi:10.1002/bit.260450609.

[11] Y. Pu, T. Treasure, R. Gonzalez, R.A. Venditti, H. Jameel, Autohydrolysis Pretreatment of Mixed Softwood to Produce Value Prior to Combustion, Bioenerg. Res. 6 (2013) 1094-1103. doi:10.1007/s12155-013-9343-2.

[12] T.E. Amidon, B. Bujanovic, S. Liu, J.R. Howard, Commercializing Biorefinery Technology: A Case for the Multi-Product Pathway to a Viable Biorefinery, Forests. 2 (2011) 929-947. doi:10.3390/f2040929.

[13] T.L. Chaffee, Potential for enhanced properties of wood products by hot water extraction of low-value, undebarked ponderosa pine, SUNY College of Environmental Science \& Forestry, 2011.

[14] M.R. Pelaez-Samaniego, V. Yadama, E. Lowell, T.E. Amidon, T.L. Chaffee, Hot water extracted wood fiber for production of wood plastic composites (WPCs), Holzforschung. 67 (2013) 193-200. doi:10.1515/hf-2012-0071.

[15] M.R. Pelaez-Samaniego, V. Yadama, T. Garcia-Perez, E. Lowell, T. Amidon, Effect of hot water extracted hardwood and softwood chips on particleboard properties, Holzforschung. 68 (n.d.). doi:10.1515/hf-2013-0150.

[16] A. Hasan, B. Bujanovic, T. Amidon, Strength Properties of Kraft Pulp Produced from Hot-Water Extracted Woodchips Within the Biorefinery, J Biobased Mat Bioenergy. 4 (2010) 46-52. doi:10.1166/jbmb.2010.1064.

[17] H. Lu, R. Hu, A. Ward, T.E. Amidon, B. Liang, S. Liu, Hot-water extraction and its effect on soda pulping of aspen woodchips, Biomass and Bioenergy. 39 (2012) 5-13. doi:10.1016/j.biombioe.2011.01.054.

[18] G.V. Duarte, B.V. Ramarao, T.E. Amidon, P.T. Ferreira, Effect of Hot Water Extraction on Hardwood Kraft Pulp fibers (Acer saccharum, Sugar Maple), Ind. Eng. Chem. Res. 50 (2011) 9949-9959. doi:10.1021/ie200639u.

[19] X. Chen, M. Lawoko, A.V. Heiningen, Kinetics and mechanism of autohydrolysis of hardwoods, Bioresource Technology. 101 (2010) 7812-7819. doi:10.1016/j.biortech.2010.05.006.

[20] M.R. Pelaez-Samaniego, V. Yadama, E. Lowell, R. Espinoza-Herrera, A review of wood thermal pretreatments to improve wood composite properties, Wood Sci Technol. 47 (2013) 1285-1319. doi:10.1007/s00226-013-0574-3.

[21] H.L. Chum, D.K. Johnson, S.K. Black, R.P. Overend, Pretreatment-Catalyst effects and the combined severity parameter, Applied Biochemistry and Biotechnology. 24-25 (1990) 1-14. doi:10.1007/BF02920229.

[22] S. Liu, Woody biomass: Niche position as a source of sustainable renewable chemicals and energy and kinetics of hot-water extraction/hydrolysis, Biotechnology Advances. 28 (2010) 563-582. doi:10.1016/j.biotechadv.2010.05.006.

[23] E12 Committee, Standard Practice for Calculation of Color Tolerances and Color Differences from Instrumentally Measured Color Coordinates, 2012 ed., ASTM International, West Conshohocken, PA, 2011. doi:10.1520/D2244-11.

[24] L. Kumar, V. Arantes, R. Chandra, J. Saddler, The lignin present in steam pretreated softwood binds enzymes and limits cellulose accessibility, Bioresource Technology. 103 (2012) 201-208. doi:10.1016/j.biortech.2011.09.091.

[25] T. Runge, P. Wipperfurth, C. Zhang, Improving biomass combustion quality using a liquid hot water treatment, Biofuels. 4 (2013) 73-83. doi:10.4155/bfs.12.70. 
[26] O. Hosseinaei, S. Wang, A.A. Enayati, T.G. Rials, Effects of hemicellulose extraction on properties of wood flour and wood-plastic composites, Composites Part a: Applied

Science and Manufacturing. 43 (2012) 686-694.

doi:10.1016/j.compositesa.2012.01.007.

[27] M.E. Vallejos, M.D. Zambon, M.C. Area, A.A. da Silva Curvelo, Low liquid-solid ratio (LSR) hot water pretreatment of sugarcane bagasse, Green Chem. 14 (2012) 1982-1989. doi:10.1039/C2GC35397K.

[28] C. Li, G. Cheng, V. Balan, M.S. Kent, M. Ong, S.P.S. Chundawat, et al., Influence of physico-chemical changes on enzymatic digestibility of ionic liquid and AFEX pretreated corn stover, Bioresource Technology. 102 (2011) 6928-6936. doi:10.1016/j.biortech.2011.04.005.

[29] Y. Zhang, O. Hosseinaei, S. Wang, Z. Zhou, Influence of Hemicellulose Extraction on Water Uptake Behavior of Wood Strands, Wood and Fiber Science. 43 (2011) 244-250.

[30] P.S. Lam, S. Sokhansanj, X. Bi, C.J. Lim, S. Melin, Energy Input and Quality of Pellets Made from Steam-Exploded Douglas Fir (Pseudotsuga menziesii), Energy Fuels. 25 (2011) 1521-1528. doi:10.1021/ef101683s.

[31] J. Li, G. Henriksson, G. Gellerstedt, Lignin depolymerization/repolymerization and its critical role for delignification of aspen wood by steam explosion, Bioresource Technology. 98 (2007) 3061-3068. doi:10.1016/j.biortech.2006.10.018.

[32] M. Serapiglia, K. Cameron, A. Stipanovic, L. Smart, High-resolution Thermogravimetric Analysis For Rapid Characterization of Biomass Composition and Selection of Shrub Willow Varieties, Applied Biochemistry and Biotechnology. 145 (2008) 3-11-11. doi:10.1007/s12010-007-8061-7.

[33] Xiao, L.P., Z.J. Sun, Z.J. Shi, F. Xu, R.C. Sun, Impact of hot compressed water pretreatment on the structural changes of woody biomass for bioethanol production, Bioresources. 6 (2011) 1576-1598.

[34] W.-H. Chen, P.-C. Kuo, Torrefaction and co-torrefaction characterization of hemicellulose, cellulose and lignin as well as torrefaction of some basic constituents in biomass, Energy. 36 (2011) 803-811. doi:10.1016/j.energy.2010.12.036.

[35] V.I. Sharypov, N. Marin, N.G. Beregovtsova, S.V. Baryshnikov, B.N. Kuznetsov, V.L. Cebolla, et al., Co-pyrolysis of wood biomass and synthetic polymer mixtures. Part I: influence of experimental conditions on the evolution of solids, liquids and gases, Journal of Analytical and Applied Pyrolysis. 64 (2002) 15-28. doi:10.1016/S01652370(01)00167-X.

[36] N. Owen, D. Thomas, Infrared studies of hard and soft woods, Applied Spectroscopy. 43 (1989) 451-455.

[37] Y. Kataoka, T. Kondo, FT-IR Microscopic Analysis of Changing Cellulose Crystalline Structure during Wood Cell Wall Formation, Macromolecules. 31 (1998) 760-764. doi:10.1021/ma970768c.

[38] Ö.P. Çetinkol, D.C. Dibble, G. Cheng, M.S. Kent, B. Knierim, M. Auer, et al., Understanding the impact of ionic liquid pretreatment on eucalyptus, Biofuels. 1 (2010) 33-46. doi:10.4155/bfs.09.5.

[39] Y. Chen, Y. Fan, J. Gao, N.M. Stark, The effect of heat treatment on the chemical and color change of black locust (Robinia pseudoacacia) wood flour, Bioresources. 7 (2012) 1157-1170. doi: 10.15376/biores.7.2.2236-2248.

[40] D. Fengel, G. Wegener, Wood: chemistry, ultrastructure, reactions, de Gruyter, 1983. 
[41] B. Sundqvist, Colour changes and acid formation in wood during heating, Luleå tekniska universitet, 7 (2004) 2236-2248. 
Tables

Table 1 - RSM experimental design and results obtained for dependent variables on mass removal and HEY.

\begin{tabular}{|c|c|c|c|c|c|c|}
\hline \multirow[b]{2}{*}{$\begin{array}{l}\text { Serial } \\
\text { Number }\end{array}$} & \multicolumn{2}{|c|}{ Independent variables $^{\mathrm{a}}$} & \multicolumn{4}{|c|}{ Responses } \\
\hline & $\begin{array}{l}\text { Time }(\min ) \\
X_{1}\left(x_{1}\right)\end{array}$ & $\begin{array}{l}\text { Temperature }\left({ }^{\circ} \mathrm{C}\right) \\
X_{2}\left(x_{2}\right)\end{array}$ & SF & $\begin{array}{l}\text { Mass removal } \\
(\%)\end{array}$ & $\mathrm{HEY}^{\mathrm{b}}$ & $\mathrm{HEY}^{\mathrm{c}}$ \\
\hline 1 & $30(-1)$ & $140(-1)$ & 2.65 & 3.08 & 24.42 & 16.91 \\
\hline 2 & $30(-1)$ & $180(1)$ & 3.83 & 16.70 & 61.17 & 59.41 \\
\hline 3 & $30(-1)$ & $160(0)$ & 3.24 & 9.36 & 19.29 & 28.55 \\
\hline 4 & $120(1)$ & $140(-1)$ & 3.26 & 7.56 & 37.87 & 37.29 \\
\hline 5 & $120(1)$ & $180(1)$ & 4.43 & 22.72 & 56.65 & 61.83 \\
\hline 6 & $120(1)$ & $160(0)$ & 3.85 & 18.48 & 44.57 & 39.95 \\
\hline 7 & $75(0)$ & $140(-1)$ & 3.05 & 5.86 & 25.79 & 33.86 \\
\hline 8 & $75(0)$ & $180(1)$ & 4.23 & 20.86 & 70.81 & 67.38 \\
\hline 9 & $75(0)$ & $160(0)$ & 3.64 & 14.34 & 41.12 & 41.01 \\
\hline 10 & $75(0)$ & $160(0)$ & 3.64 & 14.12 & 40.51 & 41.01 \\
\hline 11 & $75(0)$ & $160(0)$ & 3.64 & 15.35 & 44.47 & 41.01 \\
\hline 12 & $75(0)$ & $160(0)$ & 3.64 & 16.01 & 42.59 & 41.01 \\
\hline
\end{tabular}

${ }^{\mathrm{a}} X_{1}$ and $X_{2}$ are actual values, $x_{1}$ and $x_{2}$ are coded values.

${ }^{\mathrm{b}}$ Experimental value.

${ }^{\mathrm{c}}$ Model predicted value.

Table 2 - Chemical compositions of solid substrates and monosugar concentrations in hydrolysate after HWE pretreatment.

\begin{tabular}{|c|c|c|c|c|c|c|c|c|c|}
\hline \multirow{2}{*}{ Serial Number } & \multicolumn{5}{|c|}{ Solid substrate $\%(\mathrm{dwb})^{\mathrm{a}, \mathrm{b}}$} & \multicolumn{4}{|c|}{ Hydrolysate $(\mathrm{g} / \mathrm{L})^{\mathrm{c}}$} \\
\hline & Gl & Xyl/Mann & Ara & Gala & $\mathrm{K} 1$ & Gl & Xyl/Man & Ara & Gala \\
\hline Control & 47.81 & 15.12 & 1.28 & 3.30 & 25.83 & - & - & - & - \\
\hline 1 & 50.42 & 10.28 & 1.30 & 3.31 & 25.37 & 0.85 & 0.65 & 2.37 & 1.29 \\
\hline 2 & 51.45 & 5.64 & 0.58 & 1.43 & 29.74 & 4.83 & 9.77 & 2.02 & 4.27 \\
\hline 3 & 58.48 & 13.59 & 0.07 & 2.24 & 25.39 & 2.73 & 9.10 & 2.46 & 2.88 \\
\hline 4 & 49.44 & 9.11 & 0.57 & 2.56 & 25.63 & 2.20 & 4.38 & 2.97 & 2.96 \\
\hline 5 & 51.28 & 6.53 & 0.46 & 1.55 & 29.41 & 7.14 & 9.69 & 1.41 & 4.20 \\
\hline 6 & 51.23 & 9.24 & 0.00 & 1.68 & 30.86 & 5.37 & 14.98 & 1.73 & 3.97 \\
\hline 7 & 49.76 & 11.81 & 0.25 & 2.56 & 26.05 & 1.55 & 2.94 & 2.28 & 2.28 \\
\hline 8 & 57.84 & 5.47 & 0.00 & 0.28 & 32.33 & 5.75 & 15.69 & 1.35 & 4.08 \\
\hline 9-12 (average) & 54.81 & 10.65 & 0.00 & 0.95 & 25.82 & 4.07 & 13.69 & 1.97 & 4.21 \\
\hline
\end{tabular}

${ }^{a}$ Based on dwb of extractive-free biomass.

${ }^{\mathrm{b}}$ Gl-glucan; Xyl/Mann-xylan/mannan; Ara-arabinan; gala-galactan; and KL-klason lignin.

${ }^{c}$ Gl-glucose; Xyl/Mann-xylose/mannose; Ara-arabinose and gala-galactose. 
Table 3 - ANOVA for HEY model as a function of reaction time $\left(x_{1}\right)$ and temperature $\left(x_{2}\right)$.

\begin{tabular}{cccccc}
\hline Source & $\begin{array}{c}\text { Sum of } \\
\text { Squares }\end{array}$ & $\begin{array}{c}\text { Degree of } \\
\text { Freedom }\end{array}$ & $\begin{array}{c}\text { Mean } \\
\text { square }\end{array}$ & $F$-Value & $p$-Value \\
\hline Model & 2245.11 & 5 & 449.02 & 9.44 & $0.0082^{\mathrm{a}}$ \\
$x_{1}$ & 195.05 & 1 & 195.05 & 4.1 & 0.0893 \\
$x_{2}$ & 1685.05 & 1 & 1685.0 & 35.43 & $0.001^{\mathrm{a}}$ \\
$x_{1} x_{2}$ & 80.73 & 1 & 80.73 & 1.7 & 0.2404 \\
$x_{1}^{2}$ & 121.77 & 1 & 121.77 & 2.56 & 0.1607 \\
$x_{2}^{2}$ & 246.4 & 1 & 246.4 & 5.18 & 0.0631 \\
Error & 285.38 & 6 & 47.56 & & \\
Total & 2530.49 & 11 & & & \\
\hline
\end{tabular}

${ }^{\mathrm{a}}$ Significant.

Table 4 - Assignments of bands in Fourier transform-infrared spectra $[35,36]$.

\begin{tabular}{|l|l|l|}
\hline $\begin{array}{l}\text { Band } \\
\text { number }\end{array}$ & $\begin{array}{l}\text { Wavenumber } \\
\left(\mathrm{cm}^{-1}\right)\end{array}$ & Assignments \\
\hline 1 & 1733 & $\begin{array}{l}\text { C=O stretch in unconjugated ketones, carbonyls and ester groups; C=O in } \\
\text { xylan acetates (hemicelluloses) }\end{array}$ \\
\hline 2 & 1662 & Absorbed O-H and conjugated C-O \\
\hline 3 & 1600 & Aromatic skeletal vibration plus $\mathrm{C}=\mathrm{O}$ stretch \\
\hline 4 & 1509 & Aromatic skeletal vibration plus $\mathrm{C}=\mathrm{O}$ stretch \\
\hline 5 & 1456 & C-H deformation; asymmetric in $-\mathrm{CH}_{3}$ and $-\mathrm{CH}_{2}$ \\
\hline 6 & 1423 & Aromatic skeletal vibration combined with $\mathrm{C}-\mathrm{H}$ in phase deformation \\
\hline 7 & 1371 & C-H deformation in cellulose and hemicelluloses \\
\hline 8 & 1323 & Syringyl ring plus guaiacyl ring condensed \\
\hline 9 & 1267 & C-O of guaiacyl ring \\
\hline 10 & 1232 & Syringyl ring breathing and C-O stretch in lignin and xylan \\
\hline 11 & 1155 & C-O-C vibration in cellulose and hemicellulose \\
\hline 12 & 1101 & O-H association band in cellulose and hemicellulose plus \\
\hline 13 & 1056 & C-O stretching in cellulose and hemicellulose \\
\hline 14 & 1031 & $\begin{array}{l}\text { Aromatic C-H in plane deformation, guaiacyl type and C-O deformation; } \\
\text { primary alcohol }\end{array}$ \\
\hline 15 & 897 & C-H deformation in cellulose \\
\hline
\end{tabular}




\section{Figure Captions}

Fig. 1 - Scheme of biorefinery with the integration of HWE process [12].

Fig. 2 - Scheme of analytical methods for chemical composition.

Fig. 3 - Three-dimensional response surface and contour plot showing the effects of time and temperature on the mass removal of HWE process.

Fig. 4 - Effects of HWE pretreatment conditions on the chemical composition (Klason lignin, glucan and xylan/mannan) of solid substrates. (a) variation of temperature $\left({ }^{\circ} \mathrm{C}\right)$, time $=75 \mathrm{~min}$, $\mathrm{LSR}=4.5$; (b) variation of time $(\mathrm{min})$, temperature $=160^{\circ} \mathrm{C}, \mathrm{LSR}=4.5$; (c) variation of $\mathrm{LSR}$, temperature $=160{ }^{\circ} \mathrm{C}$, time $=75 \mathrm{~min}$.

Fig. 5 - Total monosugar concentrations in the hydrolysate under different severity factor.

Fig. 6 - Mass balance flow diagram on a $100 \mathrm{~kg}$ basis for the $\mathrm{HWE}$ pretreatment at $160{ }^{\circ} \mathrm{C}$ and $75 \mathrm{~min}$.

Fig. 7 - Response surface plot showing the effects of time $\left(x_{1}\right)$ and temperature $\left(x_{2}\right)$ on the hemicellulose extraction yield (HEY).

Fig. 8 - Effects of different pretreatment conditions on hygroscopicity behavior of wood. (a) effects of time; (b) effects of temperature. (Note: the numbers in the parentheses in the legends are the corresponding absorption rate $k$.)

Fig. 9 - TG and DTG curves of wood flour at different pretreatment conditions: (a) Effects of reaction time (temperature $=160{ }^{\circ} \mathrm{C}, \mathrm{LSR}=4.5$ ). (b) Effects of temperature (time $=75 \mathrm{~min}$, $\mathrm{LSR}=4.5$ ).

Fig. 10 - FT-IR spectra of Douglas fir wood flour before and after HWE pretreatment.

Fig. 11 - Effects of pretreatment conditions on the lightness and color change of wood: (a) Effects of reaction time (temperature $=160{ }^{\circ} \mathrm{C}, \mathrm{LSR}=4.5$ ). (b) Effects of temperature (time $=75$ min, LSR=4.5). (c) Visual images of wood chips HWE treated at different temperature. 
Figures

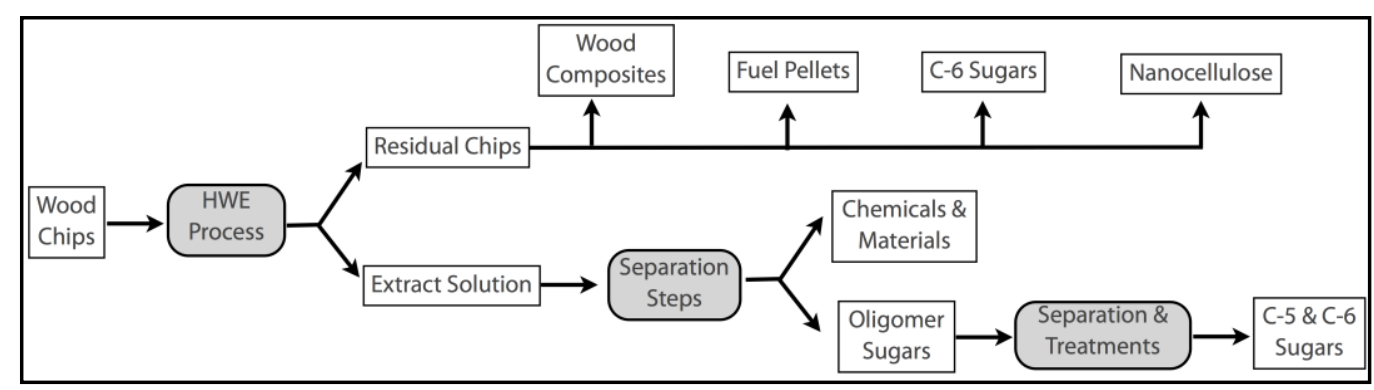

Fig. 1 


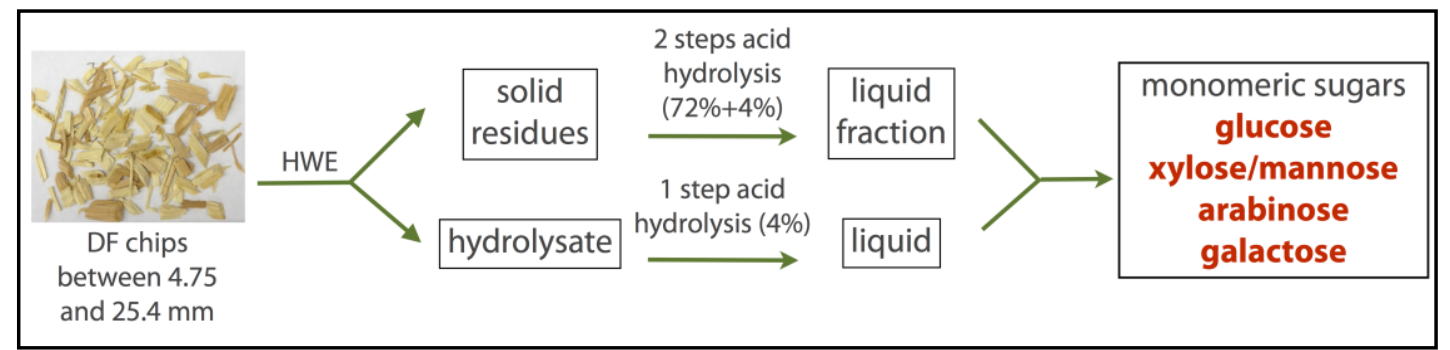

Fig. 2 


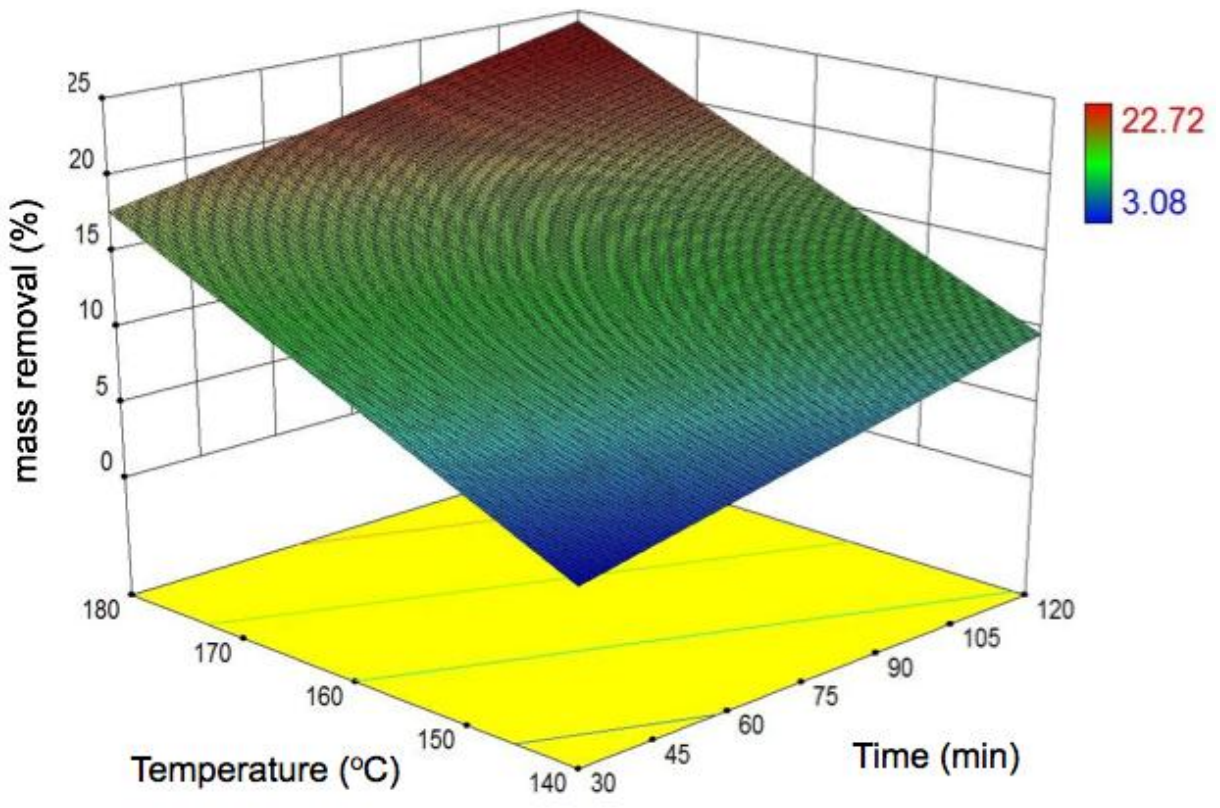

Fig. 3 


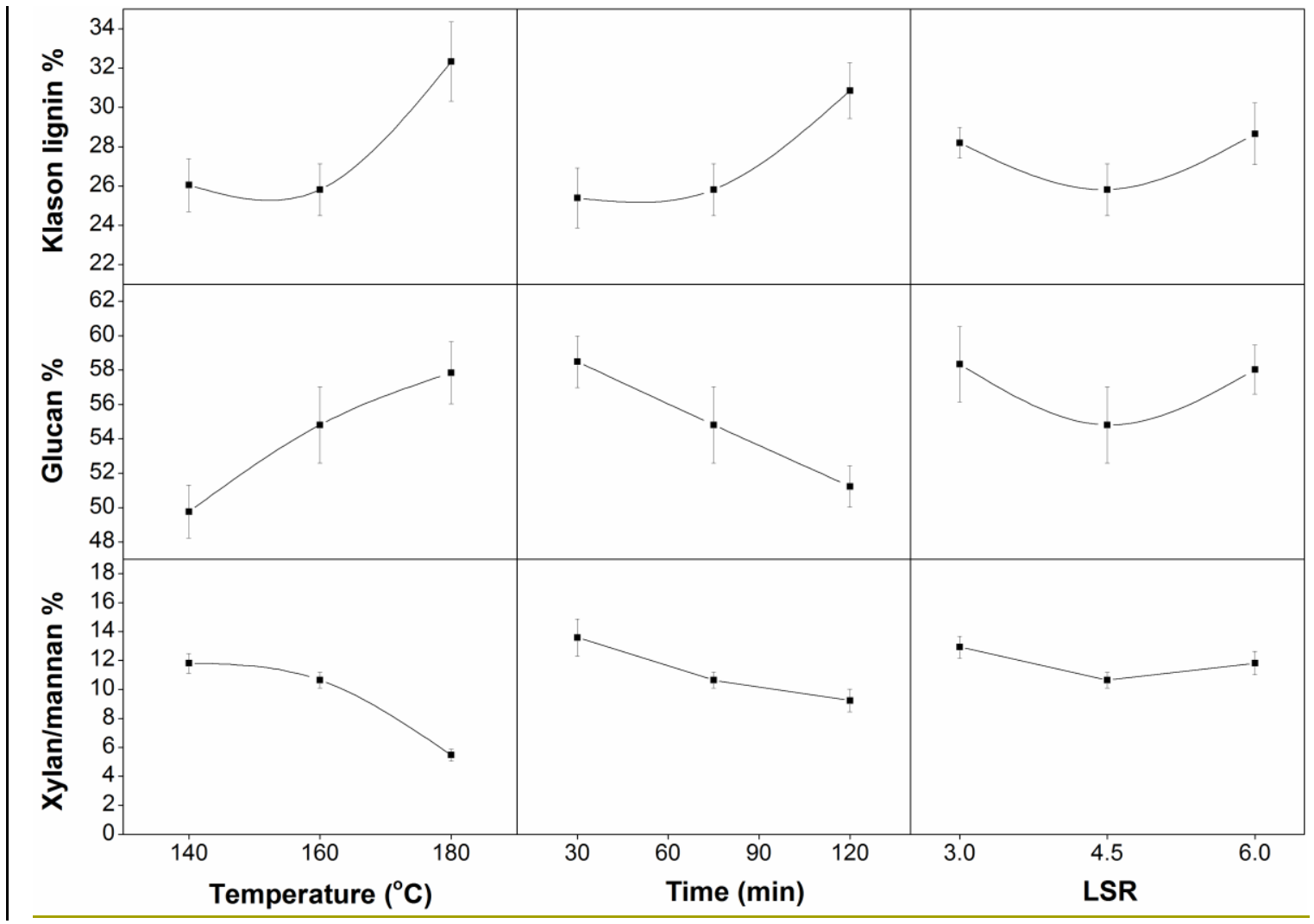

(a)

(b)

(c)

Fig. 4 


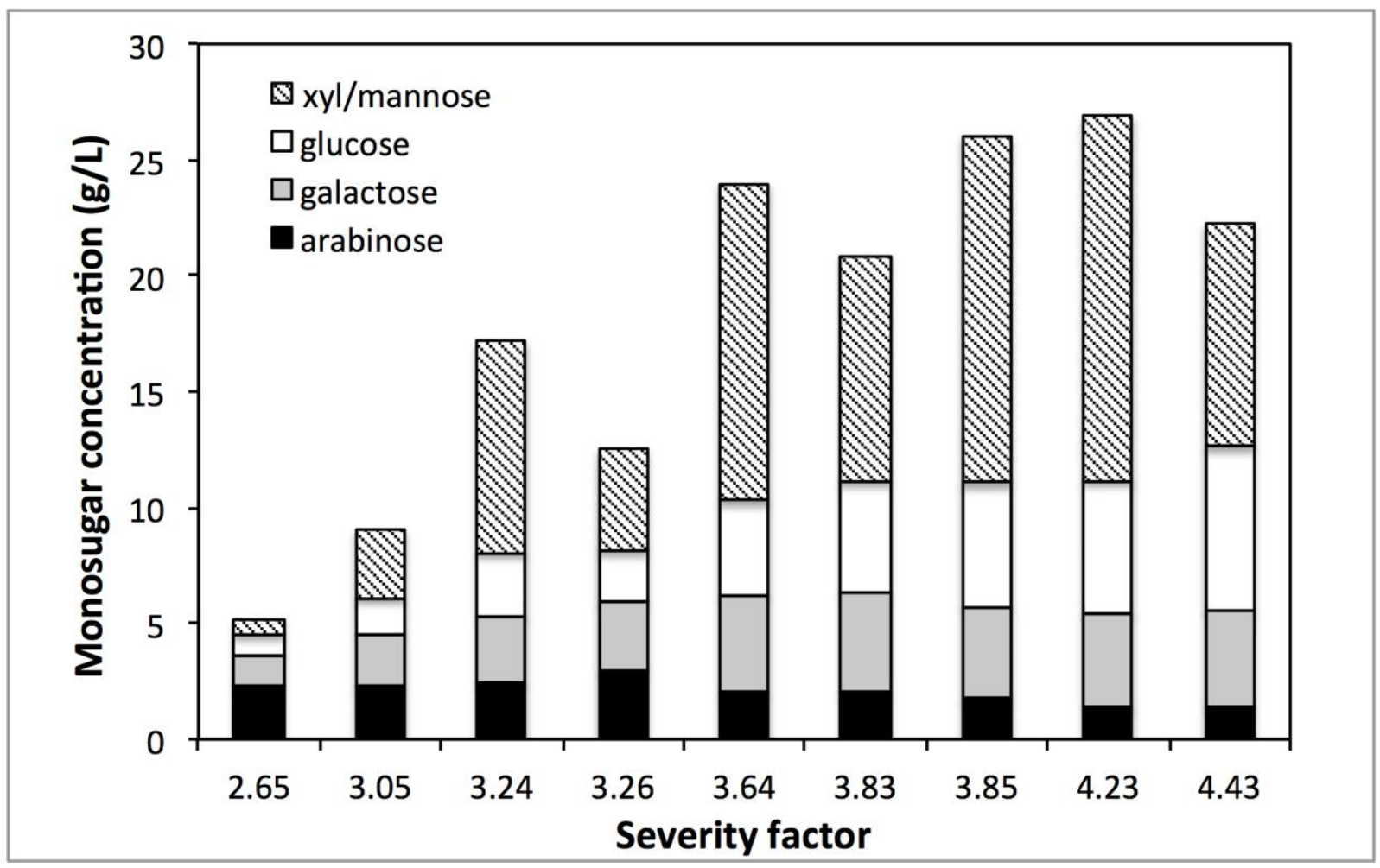

Fig. 5 


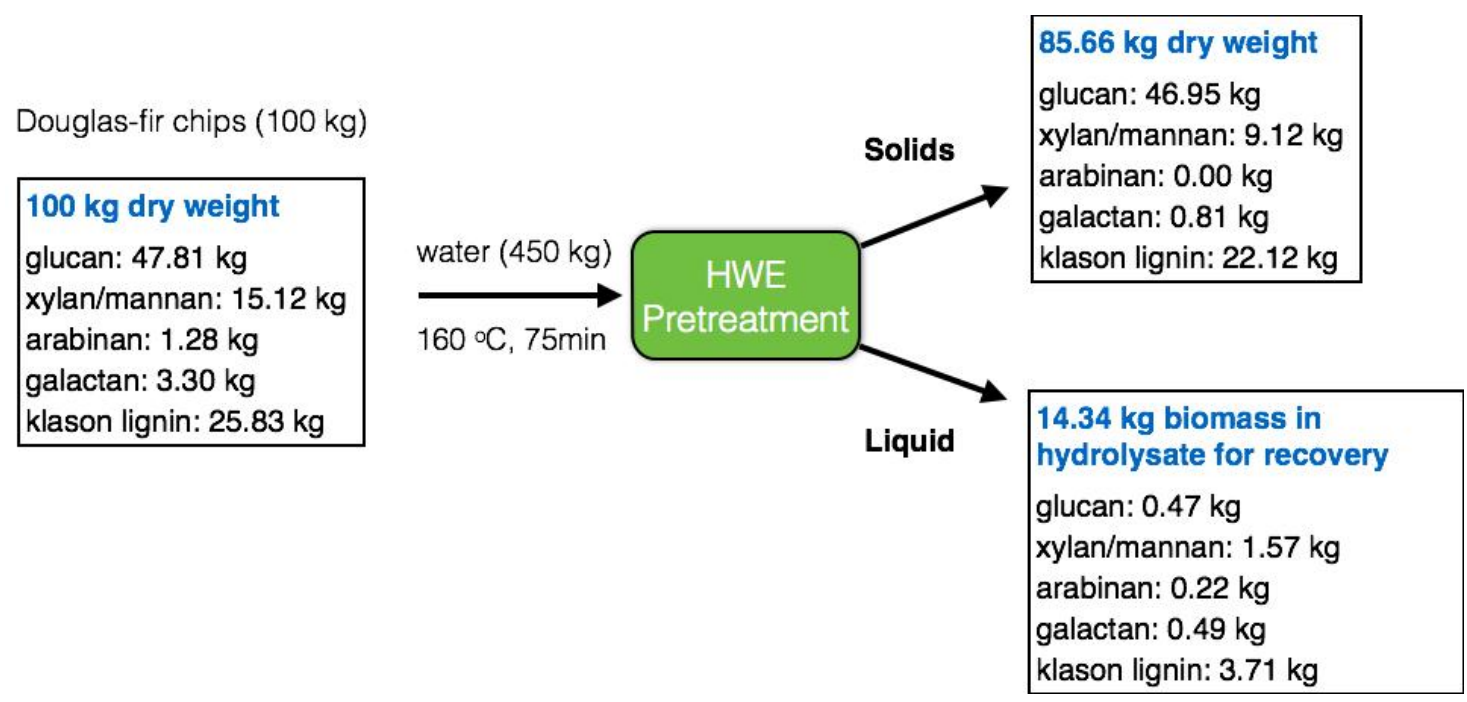

Fig. 6 


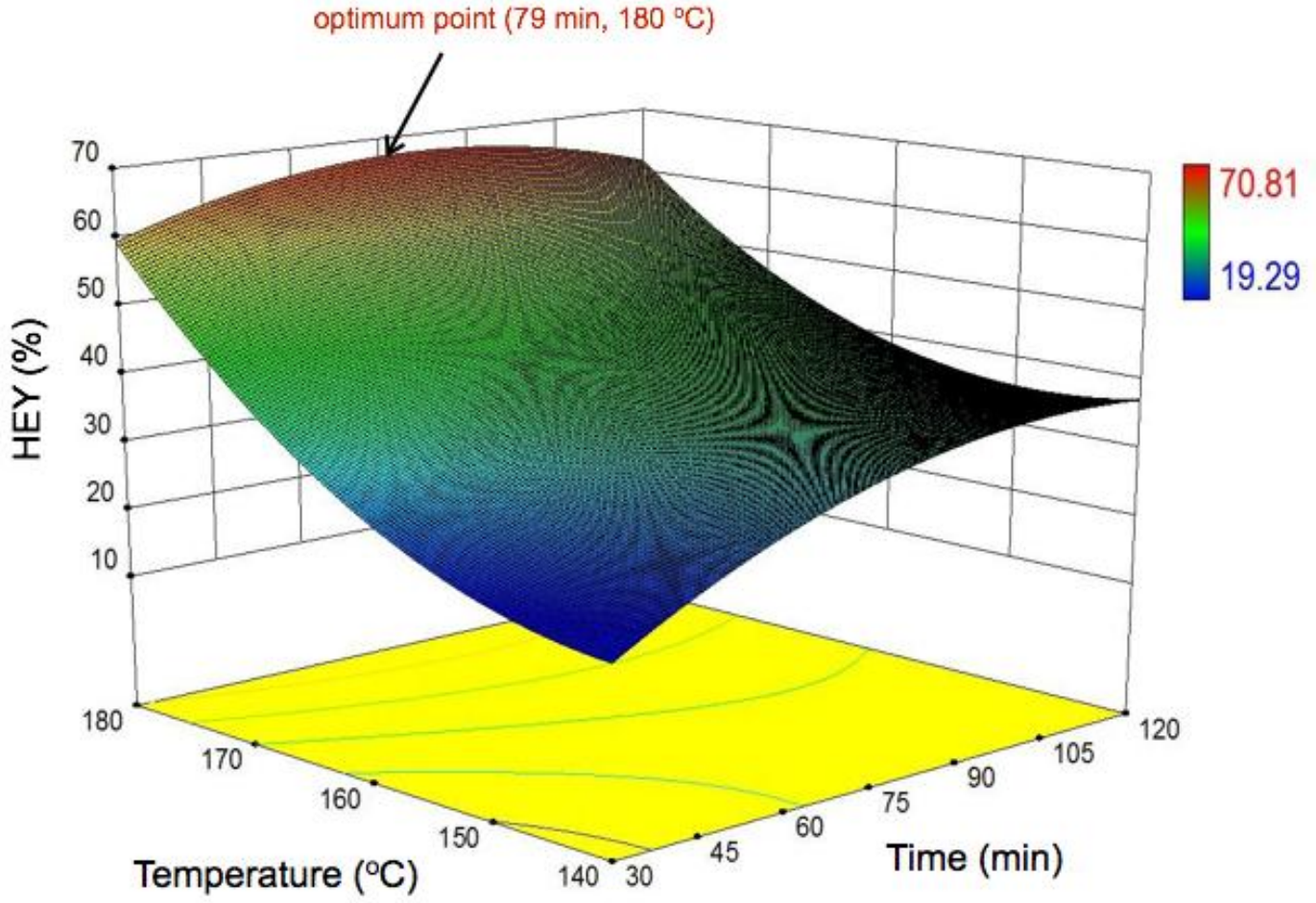

Fig. 7 


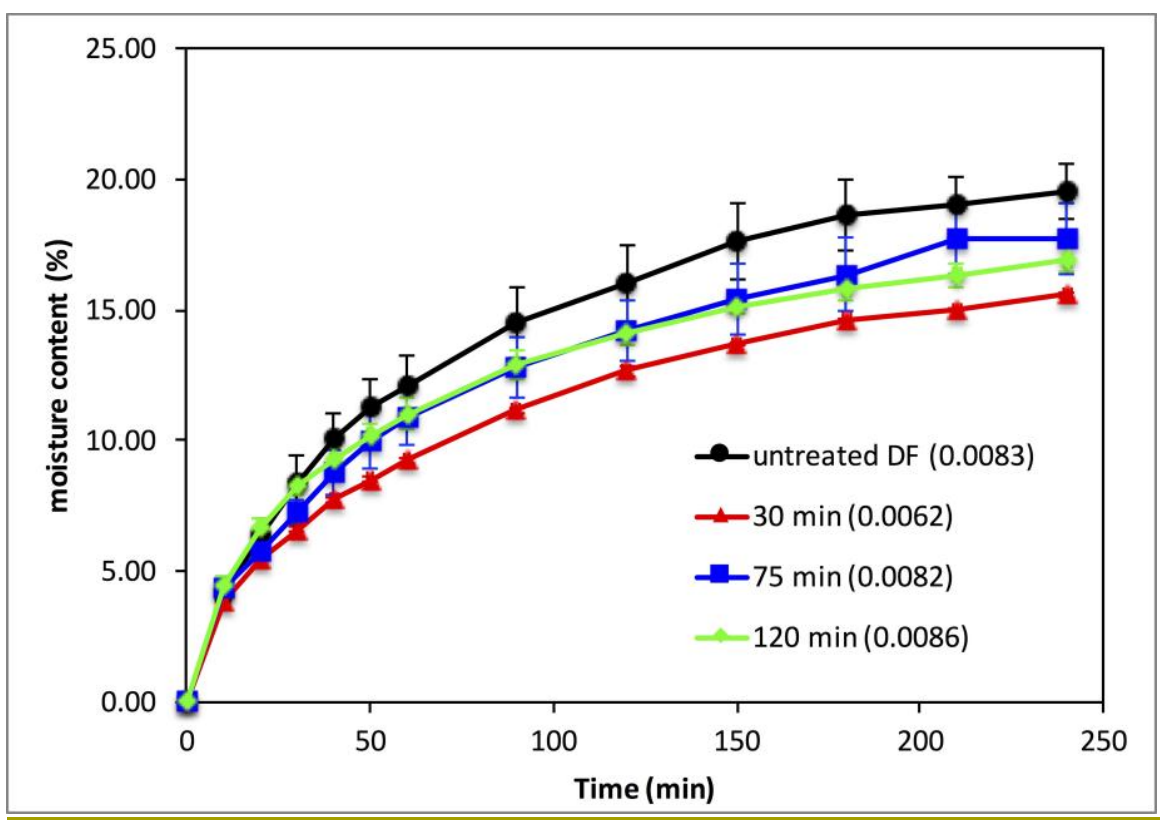

(a)

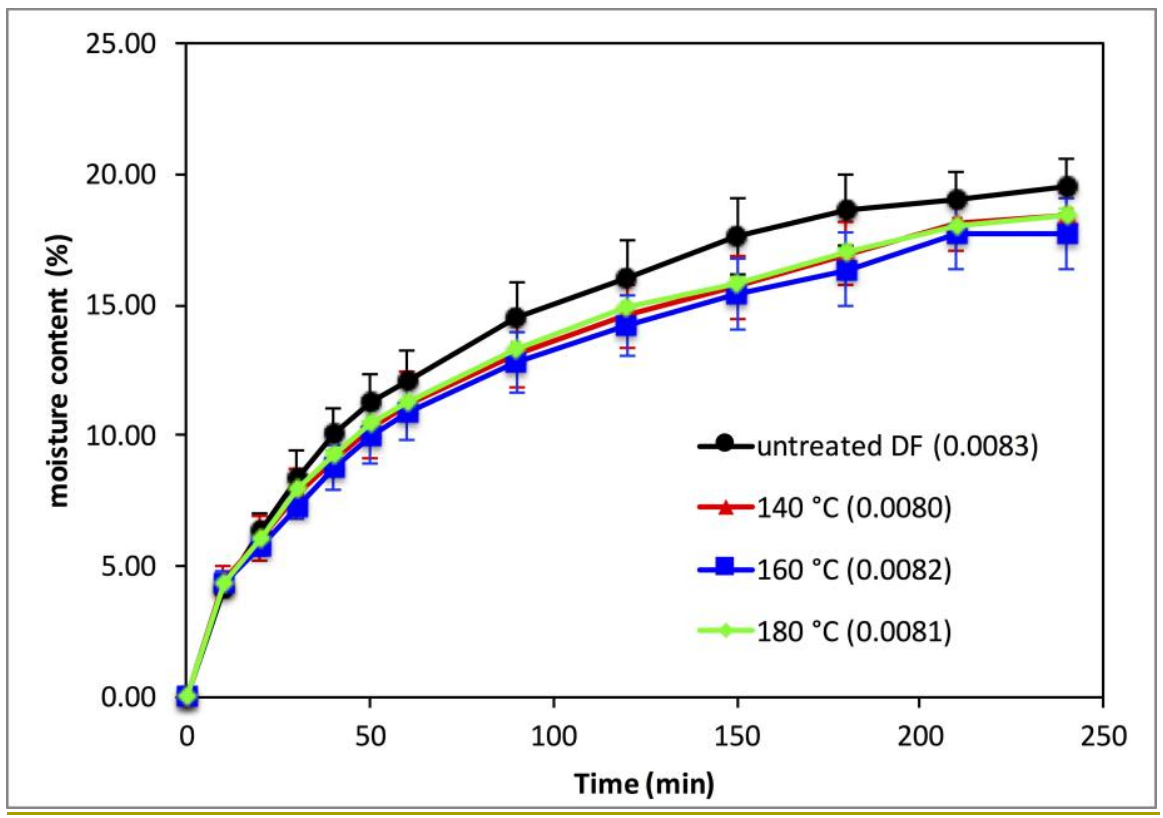

(b)

Fig. 8 

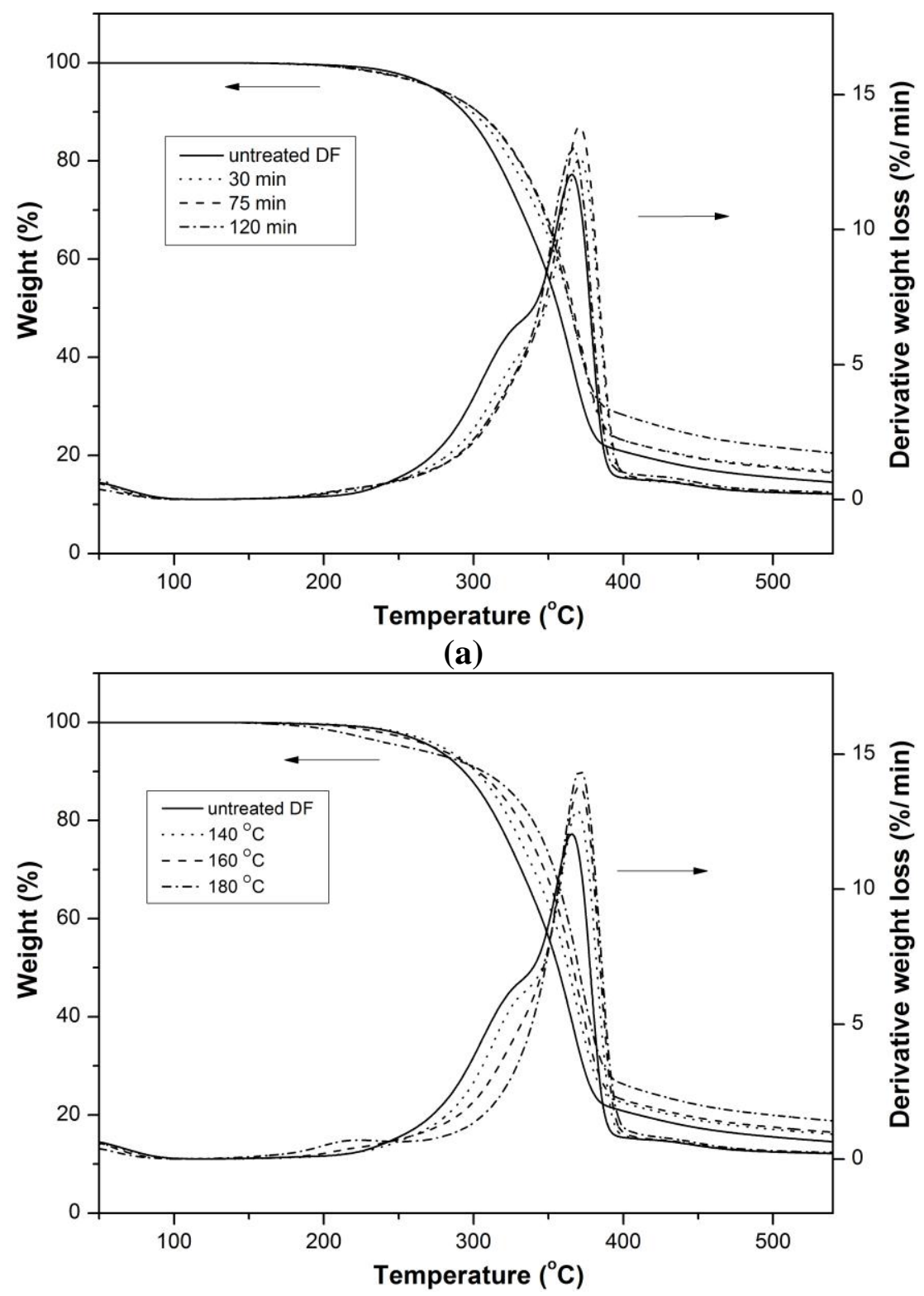

(b)

Fig. 9 


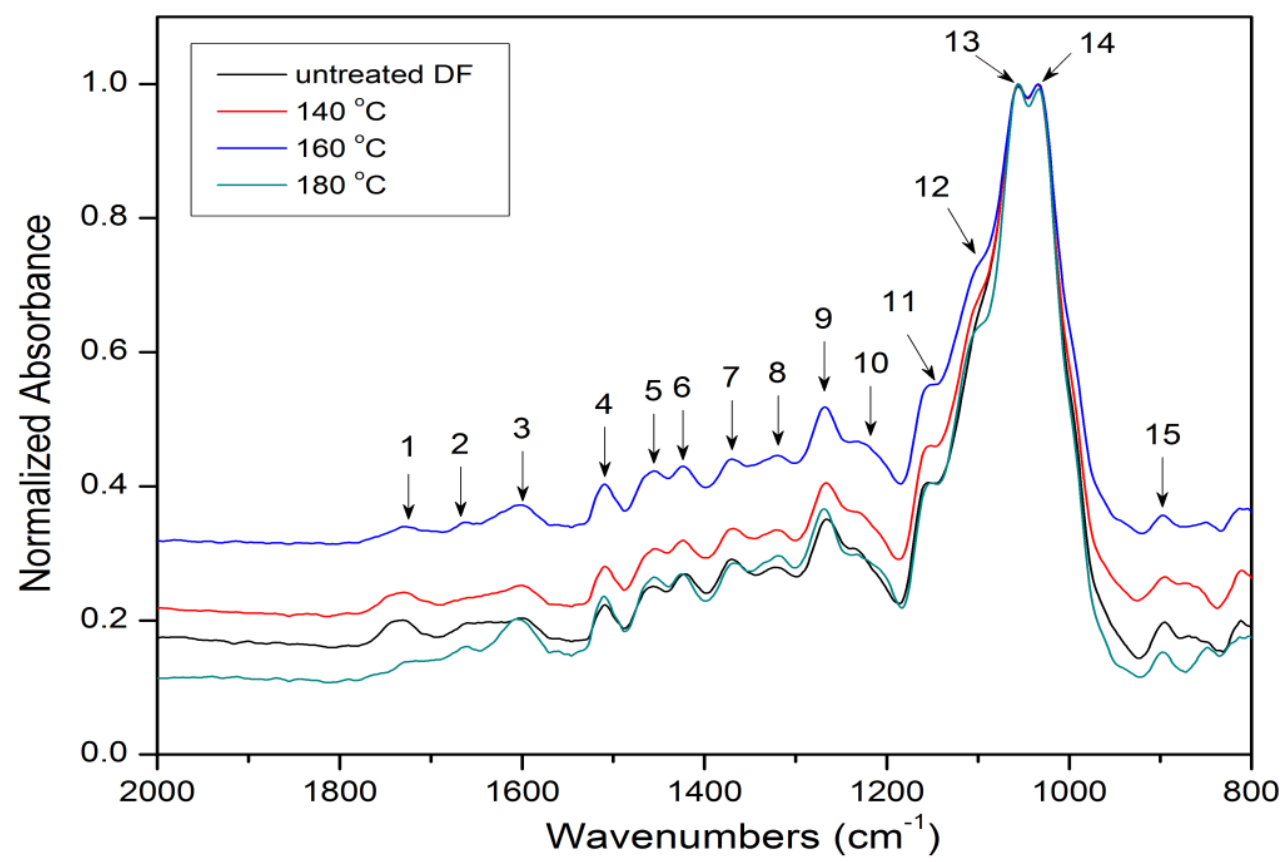

Fig. 10 


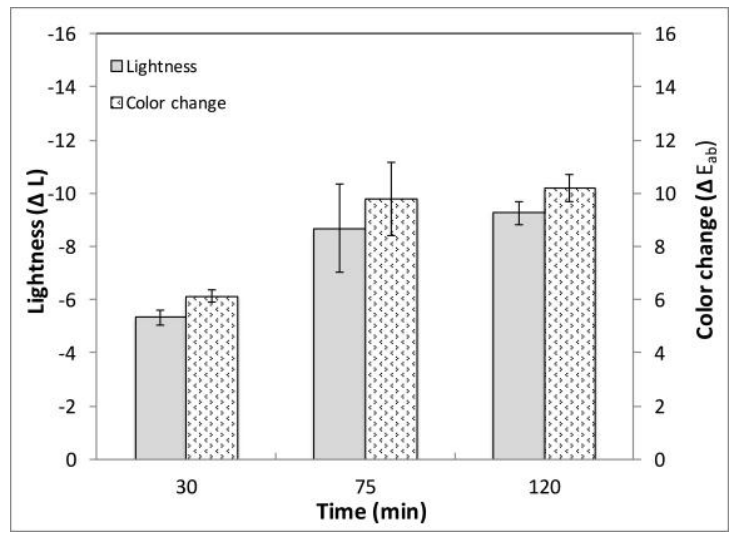

(a)

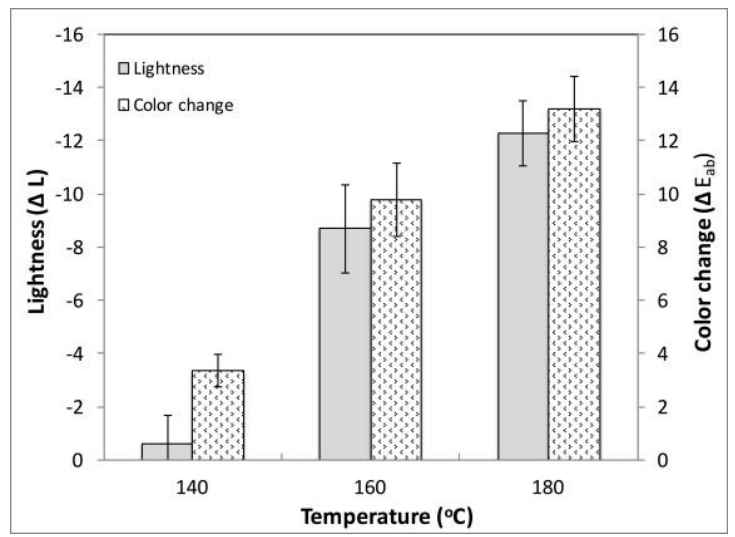

(b)

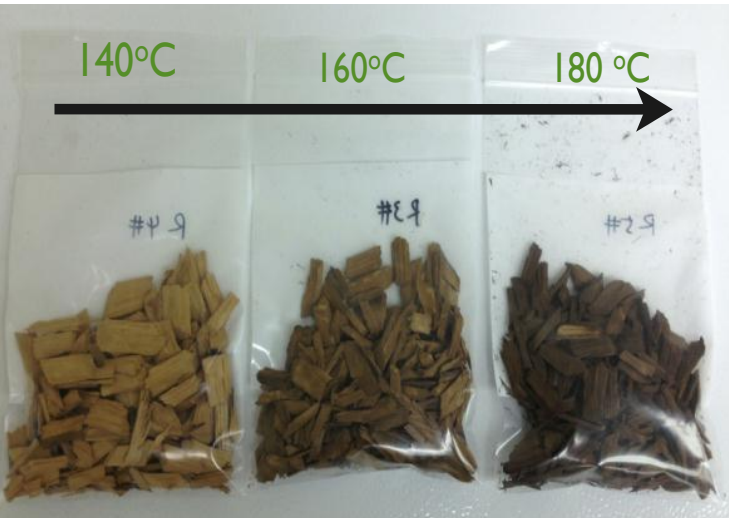

(c)

Fig. 11 